\title{
Onco-bracketology? March Madness meets today's practice
}

I have just returned from the Oncology Practice Summit, the annual conference for practice-based oncologists and midlevels, which was hosted by COMmunity Oncology and its sister publications, The Journal OF Supportive Oncology (JSO) and The Oncology Report, in Las Vegas. During my flight to the conference, I noticed that there was a certain buzz among the passengers, which I naturally assumed was about our oncology meeting. But as I looked around, I realized that not only was I the only passenger who was wearing a tie, I was also the only one who had knocked back less than one drink. The frenzy was about the first weekend of the NCAA's March Madness, and the pervasive enthusiasm among the passengers revolved around the wellknown "science" of bracketology, in which basketball enthusiasts take all 64 teams in the tournament and try to predict which team will win each match as the teams work their way down to the Final Four and ultimately, to the winner. President Obama had already said that his pick was Indiana (we know now how that

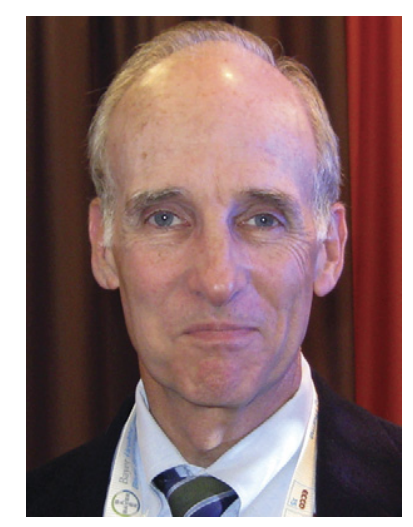
turned out - sorry Indiana), but the amateur handicappers on the plane were still sifting through the teams' records and the coaches' and individual players' strengths and weakness to bet (upon their arrival in Las Vegas) on which team would ultimately prevail. Once in Las Vegas, we managed to have our conference despite the March Madness mayhem, and in the course of the meeting, the term bracketology took on an oncology-tinged relevance for me. Bear with me.

The program for our conference this year included some incredibly current and exciting update presentations by thought leaders in oncology: Joyce O'Shaughnessy spoke on biomarkers and breast cancer; Kenneth Anderson on targeted therapies in myeloma; Jorge Cortes on managing

Commun Oncol 2013;10:101-102 DOI: 10.12788/i.cmonc.0001
CLL as a chronic disease; Lee Schwartzberg on targeted therapies and trends in oncology; and Michael Postow on BRAF, MEK, and immunotherapy treatment options in melanoma. A number of speakers focused on new developments in cancer treatments: George Kim looked at new gastrointestinal and colon cancer therapies, Ezra Cohen brought us up to date on treating head and neck cancers, Corey Langer did the same for nonsmall-cell lung cancer, and Nicholas Vogelzang spoke about integrating new drugs in the treatment of prostate cancers.

As the presenters spoke about the recent developments in molecular biology and next generation DNA sequencing, it struck me that we as oncologists have entered our own era of bracketology. We do this every day now that we have molecular markers in lung cancer (EGFR, ALK, ROS-1), colon cancer (KRAS), and breast cancer (luminal A, luminal B, classical, basal, triple negative): we "handicap" our choices of therapy, pitting old therapies against the newer targeted therapies, to maximize the positive outcomes for patients who will respond to the appropriate molecular therapy. Just 5 years ago, there were no therapies for renal cell carcinoma and melanoma, now we have molecular targets for those tumors because we have a better understanding of their biology - and there is the promise of more to come. Even the immune system is now harnessed for cancer therapy, with its potential to "unleash hell" (to quote Russell Crowe in Gladiator) with agents such as ipilimumab and the PD-1 inhibitors. So to handicap and fit the right therapy to the right patient, we're effectively practicing "onco-bracketology" on a daily basis, and more so with each new development in the field. What an exciting time to be an oncologist from a scientific standpoint, though we also hope that from an economic and practice pattern persepctive, we can continue to work in an 


\section{From the Editor}

environment in which basic care and advances in modern science will translate into longer progression-free and overall survival for our patients.

We were pleased this year to partner with our sister journal, JSO, and to be able to offer an impressive line-up of presentations on supportive care. Michael Fisch, JSO's Editor in Chief, spoke on the need for a synergy between oncology and cardiology and the goals for achieving that synergy, and Thomas Strouse, an Associate Editor on the journal, focused on integrating supportive care in the treatment of advanced cancers. Steven M. Grunberg addressed issues around symptom management in nausea and vomiting, Barbara Konkle spoke about anticoagulation and VTE, and William Goeren shared personal insights on communicating with cancer patients. Rowan Chlebowski detailed the findings of studies on the impact of diet cancer prevention, therapy, and survival, and Jennifer Klemp and Debra Patt provided a useful rationale for and "how to" advice on opening a survivorship clinic in a community practice. Audience participation was notably keen during the question sessions after the clinical and supportive presentations as well as the Clinical Conundrums (case presentations) and Daily Debate slots. For the latter, Linda Bosserman moderated a debate on value-based care and the Affordable Care Act between Russell Hoverman and Ronald Barkley, and Debra Patt and Michael Blau debated collaborations in the community oncology practice.

The Oncology Practice Summit was chaired by Lee Schwartzberg, the founding editor of Community
OnCology; the current Editors of the journal, Jame Abraham, Linda Bosserman, and Debra Patt, and JSO's Thomas Strouse, were the cochairs. In addition to their invaluable input in pulling together a program of substance and relevance for community-based oncology providers, each presented a paper or led discussions in areas that affect us on a daily basis in our practices. I thank them for their contributions.

In this month's issue, we continue with our newfound practice of onco-bracketology. We have exciting articles on recent advances in the management of advanced nonsmall-cell lung cancer by Charu Aggarwal and Corey Langer (p. 109), and on page 115, Glenn Weiss rounds out the issue with a review of applied molecular profiling and its role in evidence-based decision making for anticancer therapy.

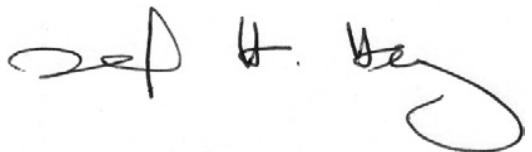

David H. Henry, MD, FACP

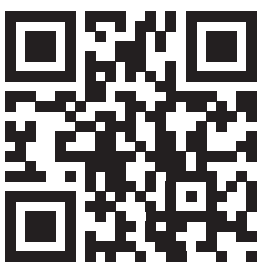

To view a video summary of the Oncology Practice Summit, scan the accompanying QR code or visit the COMMUNITY ONCOLOGY Web site at http://www.oncologypractice.com/ communityoncology/. 